\title{
Article
}

\section{Reversible Size Control of Silver Nanoclusters via Ligand-exchange}

\author{
Megalamane Siddaramappa Bootharaju, Victor M. Burlakov, Tabot M.D. Besong, Chakra P
} Joshi, Lina G. AbdulHalim, David Black, Robert Whetten, Alain Goriely, and Osman M. Bakr

Chem. Mater., Just Accepted Manuscript • DOI: 10.1021/acs.chemmater.5b00650 • Publication Date (Web): 21 May 2015

Downloaded from http://pubs.acs.org on May 25, 2015

\section{Just Accepted}

"Just Accepted" manuscripts have been peer-reviewed and accepted for publication. They are posted online prior to technical editing, formatting for publication and author proofing. The American Chemical Society provides "Just Accepted" as a free service to the research community to expedite the dissemination of scientific material as soon as possible after acceptance. "Just Accepted" manuscripts appear in full in PDF format accompanied by an HTML abstract. "Just Accepted" manuscripts have been fully peer reviewed, but should not be considered the official version of record. They are accessible to all readers and citable by the Digital Object Identifier (DOI®). "Just Accepted" is an optional service offered to authors. Therefore, the "Just Accepted" Web site may not include all articles that will be published in the journal. After a manuscript is technically edited and formatted, it will be removed from the "Just Accepted" Web site and published as an ASAP article. Note that technical editing may introduce minor changes to the manuscript text and/or graphics which could affect content, and all legal disclaimers and ethical guidelines that apply to the journal pertain. ACS cannot be held responsible for errors or consequences arising from the use of information contained in these "Just Accepted" manuscripts. 


\title{
Reversible Size Control of Silver Nanoclusters via Ligand-exchange
}

\author{
Megalamane Siddaramappa Bootharaju, ${ }^{\dagger}$ Victor M. Burlakov ${ }^{\ddagger}$ Tabot M. D. Besong, ${ }^{\dagger}$ Chakra P. \\ Joshi,${ }^{\dagger}$ Lina G. AbdulHalim, ${ }^{\dagger}$ David Black, ${ }^{\#}$ Robert Whetten, ${ }^{\#}$ Alain Goriely, ${ }^{\ddagger}$ and Osman M. \\ $\mathrm{Bakr}^{* \dagger}$
}

'Division of Physical Sciences and Engineering, Solar and Photovoltaics Engineering Research Center, King Abdullah University of Science and Technology (KAUST), Thuwal 23955-6900, Saudi Arabia,

\author{
"Mathematical Institute, University of Oxford, Woodstock Road, Oxford, OX2 6GG, UK,

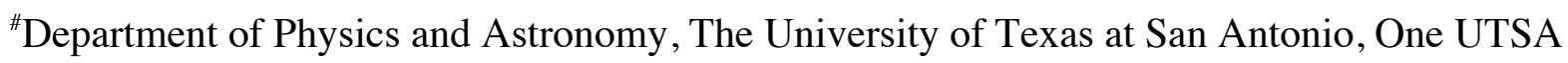 \\ Circle, San Antonio, Texas 78249, United States
}

*Corresponding author. E-mail: osman.bakr@kaust.edu.sa 


\begin{abstract}
The properties of atomically monodisperse noble metal nanoclusters (NCs) are intricately intertwined with their precise molecular formula. The vast majority of size-specific NC syntheses start from the reduction of the metal salt and thiol ligand mixture. Only in gold was it recently shown that ligand-exchange could induce the growth of NCs from one atomically precise species to another; a process of yet unknown reversibility. Here, we present a process for the ligand-exchange-induced growth of atomically precise silver NCs, in a biphasic liquid-liquid system, which is particularly of interest because of its complete reversibility and ability to occur at room temperature. We explore this phenomenon in-depth using $\operatorname{Ag}_{35}(\mathrm{SG})_{18} \quad[\mathrm{SG}=$ glutathionate $]$ and $\mathrm{Ag}_{44}(4-\mathrm{FTP})_{30}[4-\mathrm{FTP}=4$-fluorothiophenol] as model systems. We show that the ligand-exchange conversion of $\mathrm{Ag}_{35}(\mathrm{SG})_{18}$ into $\mathrm{Ag}_{44}(4-\mathrm{FTP})_{30}$ is rapid $(<5 \mathrm{~min})$ and direct, while the reverse process proceeds slowly through intermediate cluster sizes. We adapt a recently developed theory of reverse Ostwald ripening to model the NCs' interconvertibility. The model's predictions are in good agreement with the experimental observations, and they highlight the importance of small changes in the ligand-metal binding energy in determining the final equilibrium NC size. Based on the insight provided by this model, we demonstrated experimentally that by varying the choice of ligands, ligand-exchange can be used to obtain different sized NCs. The findings in this work establish ligand-exchange as a versatile tool for tuning cluster sizes.
\end{abstract}




\section{INTRODUCTION}

Atom-by-atom manipulation of quantum-sized (ca. $\leq 2 \mathrm{~nm}$ ) noble metal nanoparticles ${ }^{1-4}$ protected with monolayers of organic molecules (typically, thiolates, $-\mathrm{SR}$, and phosphines, $\mathrm{PR}_{3}$ ) yields unique size- and structure-dependent optical, ${ }^{5-7}$ chemical, ${ }^{8,9}$ and biological properties. ${ }^{10}$ Nanoparticles in this size range exhibit discrete electronic transitions in their optical spectra, akin to molecules, and are often denoted by their molecular formula, rather than their core diameter. Due to these virtues, quantum-sized nanoparticles, referred to here as nanoclusters (NCs), are also frequently termed 'molecular nanoparticles' or 'nanomolecules.' ${ }^{11-13}$ The emerging opportunities in catalysis, ${ }^{14}$ energy $,{ }^{15}, 16$ environment, ${ }^{17}$ and biology ${ }^{18}$ enabled by the small size and often precise nature of these materials has spurred researchers to explore a multitude of synthetic routes to attain them including borohydride and gaseous reduction; ${ }^{19}{ }^{20}$ nanoparticle etching ${ }^{21}$ size focusing, ${ }^{22}$ galvanic exchange ${ }^{23}$ sonochemical decomposition ${ }^{24}$ microwave ${ }^{25}$ and sunlight irradiation ${ }^{26}$; and templated growth in proteins, ${ }^{27}$ polymers,${ }^{24}$ and gel cavities.$^{26}$ Each of these methods produces size-specific NCs. Unfortunately, these recipes are rigid to varying degrees in their outcomes, and comprise ingredients, conditions, and steps that inadequately map onto deterministic control of NC size (probably due to their complex interdependence). In the long run, tractably mapping the intricate landscape of $\mathrm{NC}$ species requires the advent of methodologies endowed with simple knobs, which predictably translate into finely controlled cluster size.

Ligand-exchange on a cluster (i.e., the exchange of outgoing ligands with incoming ligands) is becoming an important approach for post-synthetically altering NC size. Depending on the NC species, ligand-exchange ${ }^{28}$ may be partial ${ }^{29}$ or complete, ${ }^{30}$ with $^{31}$ or without ${ }^{32}$ altering the metal core. Altered cores are typically a product of cluster growth ${ }^{33}$ but instances of cluster 
size shrinkage, although rare, were also reported. ${ }^{34}$ Neither case was examined for the reversibility or the extension of the process to a generalized cluster-size-tunability method. Moreover, no significant theory has been proposed to explain the mechanism underpinning such transformations in NCs.

Here, we experimentally designed and theoretically modeled a procedure for the ligandexchange-induced resizing of atomically precise silver NCs. The process occurs at room temperature in an immiscible liquid-liquid biphasic system that is remarkable for its complete reversibility. The method was studied in-depth for the interconvertibility of $\operatorname{Ag}_{35}(\mathrm{SG})_{18}[\mathrm{SG}=$ glutathionate] into $\mathrm{Ag}_{44}(4-\mathrm{FTP})_{30}[4-\mathrm{FTP}=4$-fluorothiophenol]. The reaction, depending on its direction, can be rapid and direct or may occur slowly through several transition states of intermediate NC sizes. To gain insight into the underlying mechanism for the size-selective nature of this ligand-exchange process, we modeled these phenomena within the framework of a theory for reverse coarsening. ${ }^{35}$ The model fits well with the experimental observations and highlights, among other parameters, the critical role played by small changes in the ligand-metal binding energy in determining the final size of the NC. Based on the insight provided by the model, we demonstrate experimentally that by varying the chemical structure of the incoming thiol ligands, one can tune the size of $\mathrm{Ag}_{35}(\mathrm{SG})_{18}$ to obtain a substantial set of $\mathrm{NC}$ sizes beyond $\mathrm{Ag}_{44}(4-\mathrm{FTP})_{30}$. Our findings showcase ligand-exchange as a versatile tool to explore the landscape of NC sizes, akin to size focusing in gold $\mathrm{NCs},{ }^{22}$ and provides a straightforward lever for controlling the final NC size by varying the incoming ligand. Given the diversity of metalligand interactions, this study will motivate researchers to pursue ligand-exchange as a means of generating novel NC systems in other hitherto unexplored elements. 


\section{EXPERIMENTAL SECTION}

Chemicals. All chemicals were commercially available and were used without further purification. Silver nitrate $\left(\mathrm{AgNO}_{3}, 99 \%\right)$; reduced L-glutathione (HSG, 97\%); 2fluorothiophenol (2-FTP); 4-fluorothiophenol (4-FTP); 3,4-difluorothiophenol (3,4-DFTP); 2phenylethanethiol (PET); cyclohexanethiol (CHT); 4-(trifluoromethyl)thiophenol (4-TFMTP); para-mercaptobenzoic acid (p-MBA); 4-tertiarybutylbenzylthiol (BBS); 5, $5^{1}$-dithiobis(2nitrobenzoic acid) (DTNBA); tetraphenylphosphonium bromide (TPPB); acrylamide (AR grade); N,N-methylenebisacrylamide (BIS) (AR grade); ammonium persulphate; and N,N,N $\mathrm{N}^{\mathrm{I}}, \mathrm{N}^{\mathrm{I}}$ tetramethylethylene diamine (TMED) were purchased from Sigma Aldrich. Sodium borohydride (99.99\%, Aldrich), ethanol (HPLC grade, 99.9\%, Aldrich), isopropanol, methanol, acetonitrile (HPLC grade), and dichloromethane (DCM) were used as received.

\section{Synthesis of $\operatorname{Ag}_{35}(\mathrm{SG})_{18} \mathrm{NCs}$}

Using a pestle, $23 \mathrm{mg}$ of $\mathrm{AgNO}_{3}$ was ground in an agate mortar with $200 \mathrm{mg}$ of $\mathrm{HSG}$ powder, followed by grinding with $25 \mathrm{mg}$ of $\mathrm{NaBH}_{4} \cdot{ }^{36}$ The reduction of silver thiolates caused it to change from a white to a gray powder. Clusters formed and precipitated after the addition of deionized (DI) water and excess methanol. Next, the precipitate of clusters was washed several times with methanol and then dissolved in $10 \mathrm{~mL}$ of DI water. This mixture was left for $36-48 \mathrm{~h}$ to allow for size focusing. The cluster solution was centrifuged (at $8500 \mathrm{rpm}$ for $5 \mathrm{~min}$ ) and the supernatant was concentrated by rotary evaporation. Subsequently, the NCs were precipitated and washed with methanol to remove excess ligand, silver thiolates, and other impurities that had resulted from the size-focusing step. Thus obtained clusters show a spectacular absorption band at $490 \mathrm{~nm}$. 


\section{Ligand-exchange reaction of $\operatorname{Ag}_{35}(\mathrm{SG})_{18}$ with different organic-soluble thiols}

To start, approximately $12.5 \mathrm{mM}$ DCM solutions of all thiol ligands were prepared separately. Next, $1.5 \mathrm{mg}$ of TPPB in $200 \mu \mathrm{L}$ of $\mathrm{CH}_{3} \mathrm{OH}$ was added to $1 \mathrm{~mL}$ of DCM. To this mixture, 400 $\mu \mathrm{L}$ of $12.5 \mathrm{mM}$ ligand solution was introduced; $1 \mathrm{~mL}$ of silver cluster ( $4 \mathrm{mg} / \mathrm{mL}$ DI water) was added and stirred for 5-10 min. A deepened color in the DCM phase indicated the exchange of ligands. The DCM layer was separated and centrifuged. The supernatant was concentrated, and clusters were precipitated by adding methanol or isopropanol. The precipitate of clusters was washed several times with methanol to remove any excess ligand. The conversion yields (wt $\%)$ were calculated based on the masses $(\mathrm{mg})$ of the initial and final clusters.

\section{Synthesis of $\operatorname{Ag}_{44}(\mathrm{MNBA})_{30} \mathrm{NCs}$}

$\mathrm{Ag}_{44}(\mathrm{MNBA})_{30} \mathrm{NCs}$ were synthesized according to ref [37]. Briefly, $10 \mathrm{mg}$ of DTNBA was subjected to cleavage of its S-S bond to give 5-mercapto-2-nitobenzoic acid (MNBA) in $15 \mathrm{~mL}$ of $1 \mathrm{M} \mathrm{NaOH}$ solution for $40 \mathrm{~min}$. Next, $2 \mathrm{~mL}$ of $25 \mathrm{mM}$ aq. $\mathrm{AgNO}_{3}$ was added and stirred. After $5 \mathrm{~min}$, the $\mathrm{NaBH}_{4}$ solution (1 mg in $1 \mathrm{~mL}$ of DI water) was added, resulting in a black solution. The reaction solution was stirred for $6 \mathrm{~h}$. The NCs were precipitated by adding excess methanol and cleaned 3-4 times by repeated dissolution in $1 \mathrm{M} \mathrm{NaOH}$, followed by precipitation with methanol.

\section{Synthesis of $\operatorname{Ag}_{44}(4-F T P)_{30}$ NCs}

The $\operatorname{Ag}_{44}(4-F T P)_{30}$ NCs were obtained through the ligand-exchange of $\operatorname{Ag}_{44}(\mathrm{MNBA})_{30}$ with 4FTP, as per the literature. ${ }^{30}$ Briefly, $200 \mu \mathrm{L}$ of $\mathrm{CH}_{3} \mathrm{OH}$ containing $1.5 \mathrm{mg}$ of TPPB was added into $1 \mathrm{~mL}$ of DCM; $2 \mu \mathrm{L}$ of 4-FTP was added to the above mixture. Next, $0.5 \mathrm{~mL}$ of $\mathrm{Ag}_{44}(\mathrm{MNBA})_{30} \mathrm{NCs}(\sim 10 \mathrm{mg} / \mathrm{mL})$ in $1 \mathrm{M} \mathrm{NaOH}$ solution was added and stirred at $1000 \mathrm{rpm}$ for 
2-3 min. The change of the DCM layer to dark red indicated the exchange of ligands. The DCM layer was separated and precipitated with methanol after centrifugation. The obtained precipitate was dissolved in DCM and used for further studies.

\section{Ligand-exchange reaction of $\operatorname{Ag}_{44}(4-F T P)_{30}$ with HSG}

Approximately $100 \mu \mathrm{L}$ of methanol containing $1.5 \mathrm{mg}$ of TPPB was mixed with $400 \mu \mathrm{L}$ of $\mathrm{Ag}_{44}(4-\mathrm{FTP})_{30}$ solution $(5 \mathrm{mg} / \mathrm{mL})$ in DCM. To this, an additional $1.5 \mathrm{~mL}$ of DCM was added and $750 \mu \mathrm{L}$ of $10 \mathrm{mM}$ HSG solution and $2 \mathrm{~mL}$ of DI water were added and stirred at $1200 \mathrm{rpm}$. After 4-5 h of ligand-exchange, the aqueous layer was centrifuged at $5000 \mathrm{rpm}$ and the cluster in the supernatant was precipitated by adding methanol, followed by centrifugation at $10000 \mathrm{rpm}$. The precipitate of clusters was washed several times with excess methanol to remove any excess HSG.

Polyacrylamide gel electrophoresis of $\mathrm{Ag}_{35}(\mathrm{SG})_{18}$ and HSG-exchanged products of $\mathbf{A g}_{44}$ (4FTP) $)_{30}$

We used a gel electrophoresis unit with a $1.5-\mathrm{mm}$ thick gel; the total contents of the resolving and stacking gels were 30 and 5\%, respectively. The eluting buffer consisted of $190 \mathrm{mM}$ glycine and $25 \mathrm{mM}$ tris-base. The aged $\mathrm{Ag}_{35}(\mathrm{SG})_{18}$ cluster was dissolved in a 5\% (v/v) glycerol-water solution at a concentration of $\sim 8 \mathrm{mg} / \mathrm{mL}$. The sample solution $(\sim 100 \mu \mathrm{L})$ was loaded onto the gel and eluted for $7 \mathrm{~h}$ at a constant voltage of $300 \mathrm{~V}$ using coolant at $0{ }^{\circ} \mathrm{C}$. Similarly, PAGE separations of HSG-exchanged products of $\mathrm{Ag}_{44}(4-\mathrm{FTP})_{30}$ were also performed.

\section{Characterization}

UV-vis absorption measurements were performed using a JAZZ spectrophotometer (Ocean Optics). Photoluminescence measurements were performed on a Jobin Yvon NanoLog 
instrument. Mass spectra of $\mathrm{Ag}_{44}(4-\mathrm{FTP})_{30}$ were collected using a Bruker MicroTOF-II. NC samples were dissolved in a mixture of DCM and acetonitrile mixture and electrosprayed. The instrument parameters were maintained as follows: mass range at 100 to 5000Da, capillary voltage at $2.5 \mathrm{kV}$ and source temperature at $70{ }^{0} \mathrm{C}$. Electrospray ionization mass spectrometry (ESI MS) of $\mathrm{Ag}_{35}(\mathrm{SG})_{18}$ and related samples were both measured on a Bruker MicroTOF mass spectrometer and a ThermoScientific LTQ-Velos Orbitrap mass spectrometer in the negative mode; data from the latter machine is presented. Source voltages were tuned to provide a gentle source environment by reducing the capillary exit-skimmer voltage differential for the purpose of minimizing fragmentation of the relatively labile $\operatorname{Ag}_{35}(\mathrm{SG})_{18}$ parent ion population. The sample was dissolved in a mixture of $5 \mathrm{mM}$ ammonium acetate and methanol $(1: 1 \mathrm{v}: \mathrm{v})$ and introduced to the source of the mass spectrometer at a flow rate of $15 \mu \mathrm{L} / \mathrm{min}$ (microspray). Matrix-assisted laser desorption ionization mass spectrometry (MALDI MS) measurements were performed using a Bruker Ultraflex MALDI time-of-flight/time-of-flight instrument in a linear positive mode. We used 2,5-dihydroxybenzoic acid (DHB) as the matrix for the AgSG clusters. Roughly $4 \mathrm{mg}$ of DHB was dissolved in $250 \mu \mathrm{L}$ of a 1:1 (v:v) mixture of methanol and DI water. MALDI measurements were made using a 1:1 (v:v) cluster:matrix were mixed and dried in a vacuum. MALDI MS of all organic-soluble silver clusters were measured using trans-2-[3-(4tertbutylphenyl)-2-methyl-2-propenylidene]malononitrile (DCTB) as the matrix. About $2.5 \mathrm{mg}$ of DCTB was dissolved in $250 \mu \mathrm{L}$ of acetonitrile. Nearly $2 \mu \mathrm{L}$ of the cluster was mixed with 100 $\mu \mathrm{L}$ of the matrix and spotted on the target followed by drying in ambient conditions. Sedimentation velocity-analytical ultracentrifugation measurements were performed using an Optima XL-A analytical ultracentrifuge from Beckman Coulter at 40000 rpm with an absorbance optical detection system and an An-60 Ti rotor. Samples were run at $20{ }^{\circ} \mathrm{C}$ and data were 
collected under intensity mode at $460 \mathrm{~nm}$ for $7 \mathrm{~h}$. The sedimentation and diffusion coefficient (s and D) distributions were determined after data analysis using the Ultrascan III (version 3.2, revision 1790). CHN elemental analysis was performed using the Flash 2000 thermo elemental analyzer. The oven and furnace temperatures were maintained at 75 and $950{ }^{\circ} \mathrm{C}$, respectively, using He carrier gas at a flow rate of $140 \mathrm{~mL} / \mathrm{min}$. Scanning electron microscopy with energy dispersive analysis of X-ray (SEM EDAX) spectra of NCs deposited on silicon wafers were collected using field-emission scanning electron microscope (FEI Quanta 600).

\section{RESULTS AND DISCUSSION \\ Characterization of $\operatorname{Ag}_{35}(\mathrm{SG})_{18} \mathrm{NCs}$}

$\mathrm{Ag}_{35}(\mathrm{SG})_{18} \mathrm{NCs}$ were synthesized according to the literature ${ }^{36}$ (see the experimental section for a detailed description of cluster synthesis and Figure S1 in the Supporting Information (SI) for its optical absorption and photoluminescence spectra). The molecular formula of the cluster was obtained using high-resolution ESI MS (Figure 1). A high intense peak of $\mathrm{m} / \mathrm{z} 1856$, which matched that reported in the literature $(\mathrm{m} / \mathrm{z} 1856)^{38}$, was observed with a 5- charge with a characteristic peak separation of $\mathrm{m} / \mathrm{z}$ 0.2, corresponding to $\mathrm{Ag}_{35}(\mathrm{SG})_{18}$ as the best possible compositional match. We assumed that the removal of $5 \mathrm{H}$ (i.e., $\left[\mathrm{Ag}_{35}(\mathrm{SG})_{18^{-}} 5 \mathrm{H}\right]^{5-}$ ) would result in an exact match between the simulated and experimental mass spectra (inset of Figure 1). The charge state of 5- and composition was further confirmed by the observation of a peak at $\mathrm{m} / \mathrm{z}$ 1860.4 due to a sodium adduct. Other minor charge states (4- and 6-) were also apparent in the ESI MS. However, only the single-crystal X-ray structure determination of the cluster would make it possible to confidently ascertain the magnitude of its core charge. A minor peak at one silver less from the formula i.e., $\left[\mathrm{Ag}_{34}(\mathrm{SG})_{18}-5 \mathrm{H}\right]^{5-}$ was also observed (Figure 1 and Figure S1B 
in SI), which could be an ionization fragment of $\operatorname{Ag}_{35}(\mathrm{SG})_{18}$. Analytical ultracentrifugation (AUC) data (Figure S1D in SI) obtained from as-prepared clusters indicated a predominant monodisperse sedimenting component at $\sim 3.7 \mathrm{~S}$.

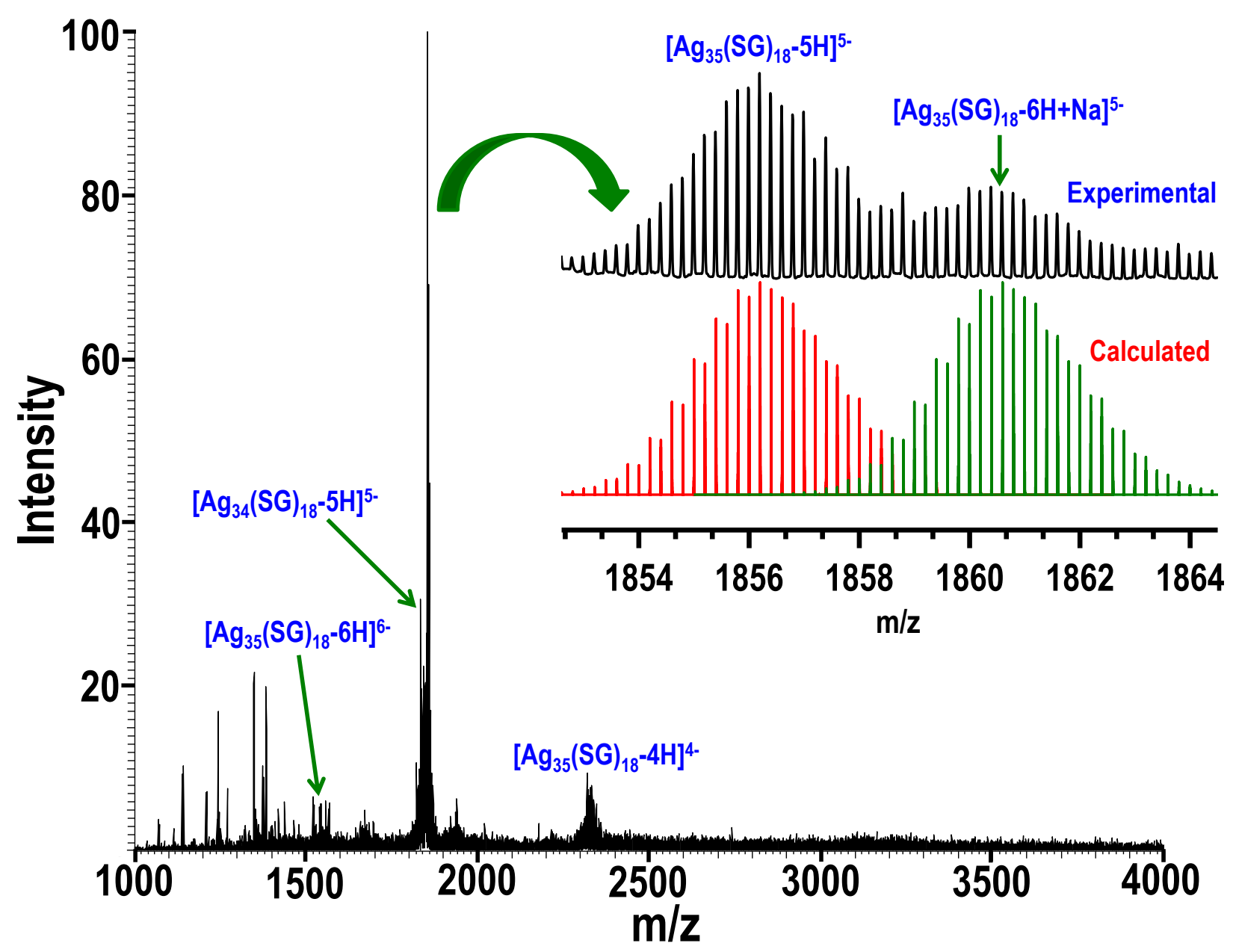

Figure 1. High-resolution ESI MS of as-prepared $\operatorname{Ag}_{35}(\mathrm{SG})_{18}$ in the negative mode. The inset shows the experimental mass spectrum compared to the simulated spectrum for $\left[\operatorname{Ag}_{35}(\mathrm{SG})_{18^{-}}\right.$ $5 \mathrm{H}]^{5-}$ and shows the best fit. The presence of a sodium adduct of a 5- charged ion (at $\left.\mathrm{m} / \mathrm{z} 1860.4\right)$ further substantiates the cluster's 5- charge state assignment. 


\section{Ligand-exchange of $\mathrm{Ag}_{35}(\mathrm{SG})_{18} \mathrm{NCs}$ with organic-soluble thiols}

Scheme 1 depicts the reaction setup for the ligand-exchange of $\mathrm{Ag}_{35}(\mathrm{SG})_{18} \mathrm{NCs}$. A DCM solution of a specific thiol (RSH) was mixed with TPPB in a glass vessel. An aqueous solution of $\mathrm{Ag}_{35}(\mathrm{SG})_{18} \mathrm{NCs}$ was then added to this mixture and subsequently stirred at room temperature (see the Experimental section for details). The color of the DCM solution (bottom layer) darkened (see the inset of Figure 2) to purple or brown (depending on the thiol ligand used) within $10 \mathrm{~min}$ of stirring, indicating the formation of ligand-exchange-induced products in the DCM phase.

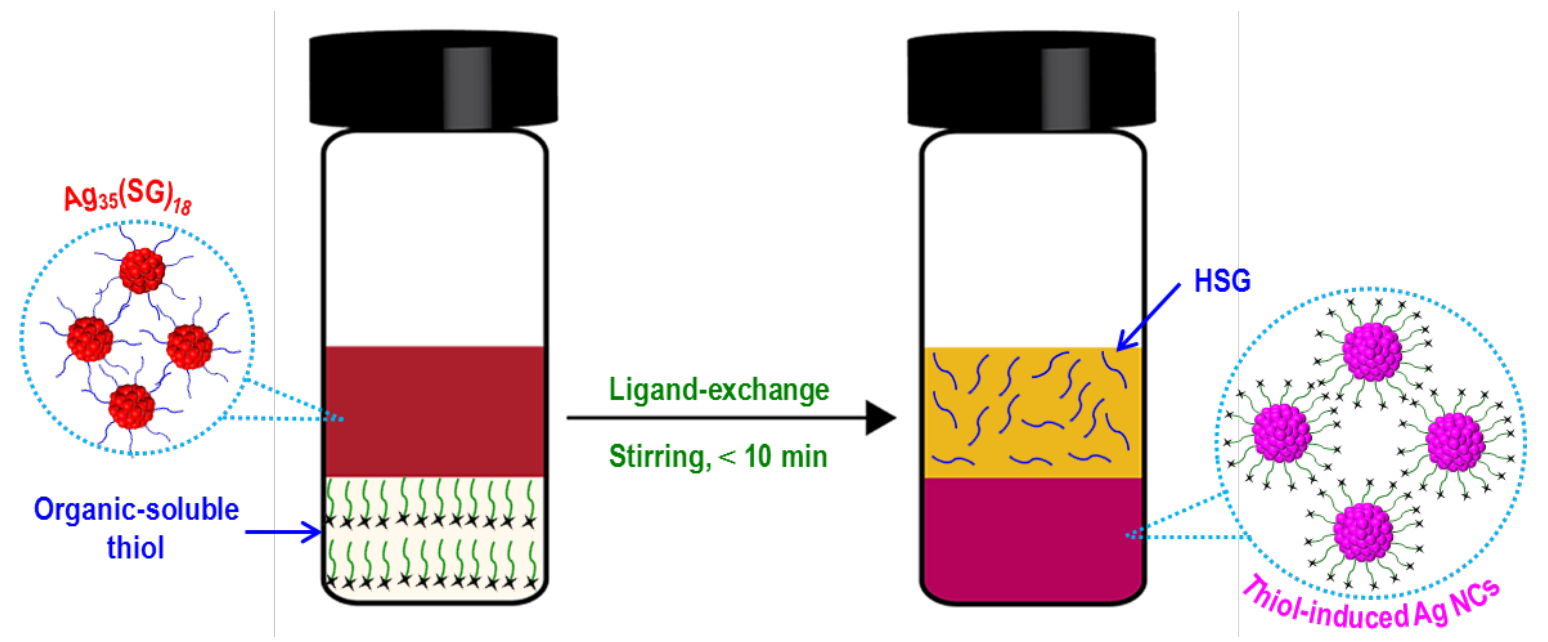

Scheme 1. A schematic of the ligand-exchange of aqueous $\mathrm{Ag}_{35}(\mathrm{SG})_{18}$ (top layer) with various organic-soluble thiols (bottom layer, organic phase). Note that sizes and shapes of ligands and clusters are not drawn to scale.

\section{Ligand-exchange-induced growth of $\mathrm{Ag}_{35}(\mathrm{SG})_{18}$ into $\mathrm{Ag}_{44}(4-\mathrm{FTP})_{30}$}

The purified ligand-exchange-induced product of $\mathrm{Ag}_{35}(\mathrm{SG})_{18}$ exhibits a characteristic absorption spectrum (Figure $2 \mathrm{~A}$ ) that matches exactly with $\mathrm{Ag}_{44}(4-\mathrm{FTP})_{30}{ }^{39}, 40 \mathrm{NCs}$ when 4-FTP 
was the organic-soluble ligand (i.e. $\mathrm{RSH}=4 \mathrm{FTP}$ ) used in the exchange. The RSH concentration is critical for a given amount of $\mathrm{Ag}_{35}(\mathrm{SG})_{18}$ to obtain a stable ligand-induced product in solution. The products were unstable when low and high 4-FTP concentrations were used in exchange, whereas the product $\operatorname{Ag}_{44}(4-\mathrm{FTP})_{30}$ was stable at moderate 4-FTP concentrations (Figure S2 in SI). The compositional assignment of $\mathrm{Ag}_{44}(4-\mathrm{FTP})_{30}$ was corroborated by ESI MS. Negative mode ESI MS data presented in Figure 2B show the presence of an intense peak at m/z 2140 corresponding to a 4- charged $\mathrm{Ag}_{44}(4-\mathrm{FTP})_{30}$ species (calculated: m/z 8560/4). Expansion of this peak has an isotopic distribution of $\left[\operatorname{Ag}_{44}(4-\mathrm{FTP})_{30}\right]^{4-}$ with a peak separation of $\mathrm{m} / \mathrm{z} 0.25$ (inset of Figure 2B), confirming the charge state of $4 .^{40}$ The exact match of the calculated and experimental mass spectra confirms the composition of $\operatorname{Ag}_{44}(4-F T P)_{30}$. The other mass peaks corresponding to triply charged $\operatorname{Ag}_{42}(4-\mathrm{FTP})_{27}$ and $\mathrm{Ag}_{43}(4-\mathrm{FTP})_{28}$ in addition to $\left[\operatorname{Ag}_{44}(4-\mathrm{FTP})_{30}\right]^{3-}$ (peaks marked with an asterisk in Figure $2 \mathrm{~B}$ ) are identified as fragments of $\left[\operatorname{Ag}_{44}(4-\mathrm{FTP})_{30}\right]^{3-}$, which are formed under ESI conditions. ${ }^{40}$ The apparent absence of any signal attributable to HSG and its complexes with $\mathrm{Ag}$ in ESI MS implies that the cluster's ligand shell comprises exclusively 4-FTP. This observation was further validated by SEM EDAX and CHN elemental analysis (Figure S3 and Table 1 in SI), which indicate the effective absence of $\mathrm{N}$ and $\mathrm{O}$, characteristic elements of HSG, and the presence of F-a signature element of 4-FTP. Sedimentation coefficient distributions of the exchanged product measured by AUC (Figure S4 in SI) show the presence of a single predominant component in solution consistent with the hypothesis of $\mathrm{a} \mathrm{Ag}_{44}(4-\mathrm{FTP})_{30}$ as the only major species in solution. Minor components with low sedimentation coefficients are attributed to byproduct $\operatorname{Ag}(4-\mathrm{FTP})$ complexes, which were also detected by ESI MS. 

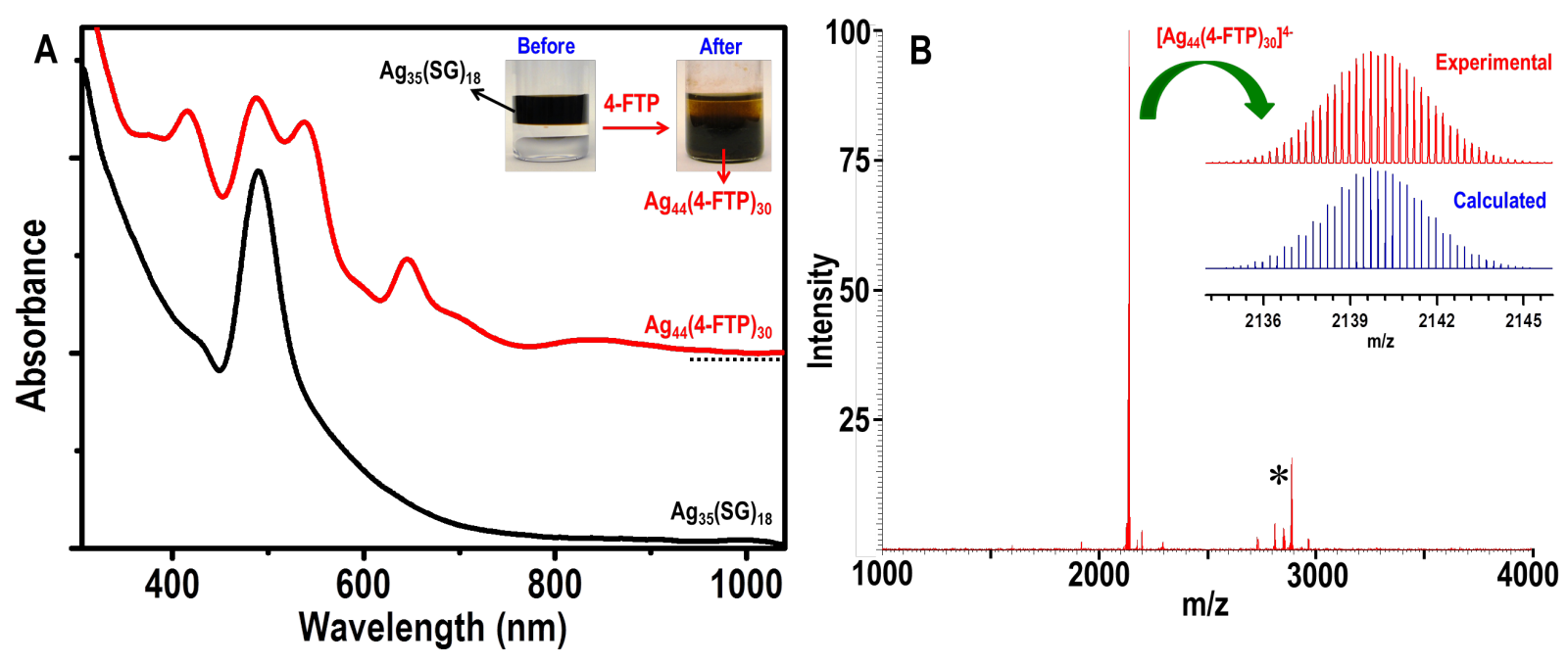

Figure 2. (A) UV-vis absorption spectra of $\mathrm{Ag}_{35}(\mathrm{SG})_{18}$ (black line) and its 4-FTP exchangeinduced product (red line). The red line was shifted vertically for clarity. Inset photographs correspond to before (left) and after (right) the ligand-exchange reaction of $\operatorname{Ag}_{35}(\mathrm{SG})_{18}$ with 4FTP. (B) Negative mode ESI MS of the 4-FTP-exchange-induced product of $\mathrm{Ag}_{35}(\mathrm{SG})_{18}$. The inset of B displays the experimental and calculated mass spectra of $\left[\operatorname{Ag}_{44}(4-F T P)_{30}\right]^{4-}$. Asterisks represent triply charged $\operatorname{Ag}_{44}(4-\mathrm{FTP})_{30}$ and its fragments.

\section{Reversing the conversion of $\operatorname{Ag}_{35}(\mathrm{SG})_{18}$ into $\operatorname{Ag}_{44}(4-F T P)_{30}$ via ligand-exchange}

After demonstrating the growth of $\operatorname{Ag}_{35}(\mathrm{SG})_{18}$ to $\mathrm{Ag}_{44}(4-\mathrm{FTP})_{30}$ by ligand-exchange, we were motivated to explore the possibility of reversing the reaction via the same method (i.e., transforming $\operatorname{Ag}_{44}(4-\mathrm{FTP})_{30}$ back to $\left.\operatorname{Ag}_{35}(\mathrm{SG})_{18}\right)$. A solution of $\operatorname{Ag}_{44}(4-\mathrm{FTP})_{30} \mathrm{NCs}$ in DCM was stirred with aqueous HSG in the presence of methanolic TPPB (inset of Figure 3A). In this protocol, TPPB facilitates the exchange of 4-FTP with HSG. The HSG-exchange-induced product of $\operatorname{Ag}_{44}(4-\mathrm{FTP})_{30}$ (obtained after $5 \mathrm{~h}$ of the reaction, referred to as $5 \mathrm{~h}$-exchanged cluster, Figure 3A) displays prominent absorption peaks at 540 and $460 \mathrm{~nm}$ and two shoulder peaks around 650 and $830 \mathrm{~nm}$. This $5 \mathrm{~h}$-exchanged cluster was separated from the reaction solution and washed repeatedly using methanol to remove excess HSG. Finally, the precipitate of the cluster 
was dissolved in DI water and placed at $4{ }^{0} \mathrm{C}$ in a fridge for $6 \mathrm{~h}$. During this period, the product was transformed into NCs with absorption features very similar to $\mathrm{Ag}_{35}(\mathrm{SG})_{18} \mathrm{NCs}$ (Figure $3 \mathrm{~A}$, red line), assumed to be reversed $\operatorname{Ag}_{35}(\mathrm{SG})_{18}$ with a $\sim 50$ wt\% yield versus the initial $\operatorname{Ag}_{44}(4-$ FTP $)_{30}$ NCs. To better understand the evolution of the size distribution of particles, polyacrylamide gel electrophoresis (PAGE) was performed on 5 h-exchanged and reversed $\mathrm{Ag}_{35}(\mathrm{SG})_{18}$ materials. PAGE bands and their UV-vis data (Figure S5 in SI) clarified that the $5 \mathrm{~h}$ exchanged cluster was a mixture of intermediate metastable NCs and an $\operatorname{Ag}_{35}(\mathrm{SG})_{18}$-like cluster (left inset, bands 1 and 2), whereas the reversed $\operatorname{Ag}_{35}(\mathrm{SG})_{18}$ material consisted of only $\operatorname{Ag}_{35}(\mathrm{SG})_{18}$ (right inset, band 3) because all the intermediate NCs sizes converged solely into $\operatorname{Ag}_{35}(\mathrm{SG})_{18}$. These observations were further supported by AUC measurements of the sedimentation coefficient distribution (Figure S6 in SI). The 5 h-exchanged cluster sample displayed a mixture of components whereas the reversed $\mathrm{Ag}_{35}(\mathrm{SG})_{18}$ sample comprised mostly one component. Reassuringly, the PL spectrum of the reversed $\mathrm{Ag}_{35}(\mathrm{SG})_{18}$ exhibited an emission peak at $650 \mathrm{~nm}$ (Figure $\mathrm{S} 7$ in SI) similar to the as-prepared $\mathrm{Ag}_{35}(\mathrm{SG})_{18} \mathrm{NCs}$. It is worth mentioning that the NCs in bands 2 and 3 (Figure S5 in SI) exhibited nearly identical PAGE positions, UV-vis absorption, and PL spectra to as-prepared $\mathrm{Ag}_{35}(\mathrm{SG})_{18}$ (Figure S1A in SI), further confirming that the NCs in those two bands were $\operatorname{Ag}_{35}(\mathrm{SG})_{18}$-like.

ESI MS analysis of the $5 \mathrm{~h}-\mathrm{HSG}$-exchanged product of $\operatorname{Ag}_{44}(4-\mathrm{FTP})_{30}$ and reversed $\mathrm{Ag}_{35}(\mathrm{SG})_{18}$ cluster was carried out to shed light on the precise compositions of the intermediate and final clusters. The $5 \mathrm{~h}$-HSG-exchanged product showed peaks corresponding to $\operatorname{Ag}_{37}(\mathrm{SG})_{21}$, $\mathrm{Ag}_{36}(\mathrm{SG})_{20}, \mathrm{Ag}_{36}(\mathrm{SG})_{19}$ and $\mathrm{Ag}_{35}(\mathrm{SG})_{18}$ as 5- ions in addition to their fragments (black line in Figure 3B and Figure S8 in SI for an expanded mass range), whereas the reversed $\operatorname{Ag}_{35}(\mathrm{SG})_{18^{-}}$ like cluster displayed peaks corresponding exclusively to $\mathrm{Ag}_{35}(\mathrm{SG})_{18}$ and its fragments under ESI 
conditions (Figure 3B, red line). This indicates that the transformation of $\operatorname{Ag}_{44}(4-\mathrm{FTP})_{30}$, via ligand-exchange with HSG, occurs through intermediates such as $\mathrm{Ag}_{37}(\mathrm{SG})_{21}$ and $\mathrm{Ag}_{36}(\mathrm{SG})_{20}$ and finally converges to $\mathrm{Ag}_{35}(\mathrm{SG})_{18}$ - the initially designated reversed $\mathrm{Ag}_{35}(\mathrm{SG})_{18}$-like cluster. In addition to the presence of $\mathrm{Ag}_{35}(\mathrm{SG})_{18}$ as the main product, mass peaks for $\mathrm{AgSG}$ complexes were also observed in the low-mass region, probably as byproducts. These observations suggest that intermediates such as $\mathrm{Ag}_{37}(\mathrm{SG})_{21}$ and $\mathrm{Ag}_{36}(\mathrm{SG})_{20}$ were formed during ligand-exchange and then ripen selectively into $\mathrm{Ag}_{35}(\mathrm{SG})_{18}$, thus confirming that $\mathrm{Ag}_{35}(\mathrm{SG})_{18}$ is formed reversibly.
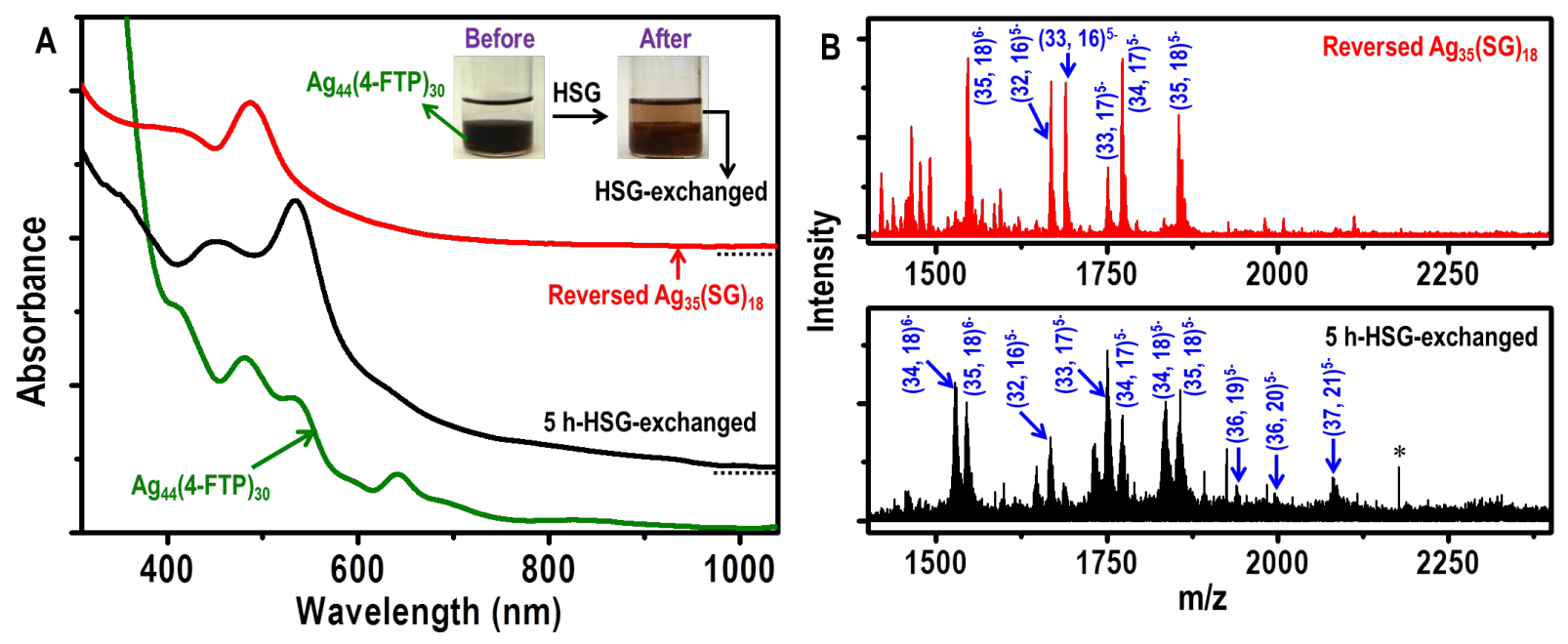

Figure 3. (A) UV-vis absorption spectra of $\mathrm{Ag}_{44}(4-F T P)_{30}$ and its HSG-exchange-induced products (5 h-exchanged and reversed $\mathrm{Ag}_{35}(\mathrm{SG})_{18}$ clusters). Inset photographs correspond to before (left) and after (right) the exchange of $\operatorname{Ag}_{44}(4-F T P)_{30}$ with HSG for $5 \mathrm{~h}$. (B) Negative mode ESI MS of the $5 \mathrm{~h}-\mathrm{HSG}$-exchanged product of $\operatorname{Ag}_{44}(4-\mathrm{FTP})_{30}$ (black line) and its completely converted $\mathrm{Ag}_{35}(\mathrm{SG})_{18}$ cluster (red line). First and second numbers in brackets correspond to silver and -SG, respectively. Peaks labeled with an asterisk have impurities and lack the isotopic resolution of silver species. Isotopic distributions of $\mathrm{Ag}_{37}(\mathrm{SG})_{21}, \mathrm{Ag}_{36}(\mathrm{SG})_{20}$, $\mathrm{Ag}_{35}(\mathrm{SG})_{18}$, and $\mathrm{Ag}_{34}(\mathrm{SG})_{18}$ are shown in Figure $\mathrm{S} 8$ in the SI. 
It is also worth noting that as a control, we separately studied the transformation of $\mathrm{Ag}_{44}(4-\mathrm{FTP})_{30}$ to $\mathrm{Ag}_{35}(\mathrm{SG})_{18}$, starting from $\operatorname{Ag}_{44}(4-\mathrm{FTP})_{30}$, which was synthesized based on a previously published report, ${ }^{30}$ in addition to $\operatorname{Ag}_{44}(4-F T P)_{30}$, which was obtained by ligandexchange from $\mathrm{Ag}_{35}(\mathrm{SG})_{18}$, as described in the previous section. In both cases the NCs behaved and transformed identically. Results from these experimental observations present consistent evidence that the reversible transformation of atomically precise silver NCs can be induced by ligand-exchange. Growth of $\mathrm{Ag}_{35}(\mathrm{SG})_{18}$ to $\mathrm{Ag}_{44}(4-\mathrm{FTP})_{30}$ occurs rapidly in a single step via ligand-exchange, whereas its reverse reaction proceeds slowly through metastable cluster sizes. The convergence or size focusing of metastable clusters into $\operatorname{Ag}_{35}(\mathrm{SG})_{18}$ is believed to occur by mass transfer from one cluster to the other (see the theoretical model in next section). The important findings are depicted in Scheme 2.

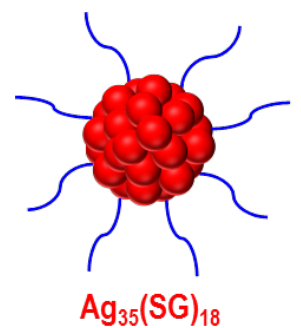

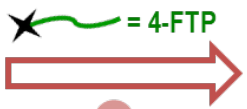

1 $\mathrm{Ag}_{35}(\mathrm{SG})_{18}$

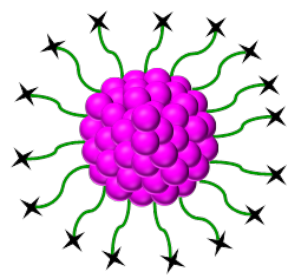

$\left[\mathrm{Ag}_{44}(4-\mathrm{FTP})_{30}\right]^{4}$
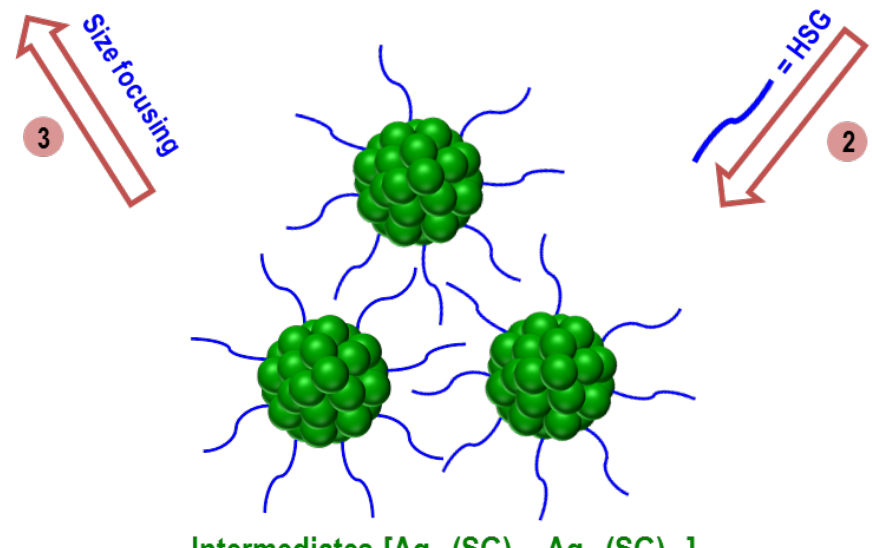

Intermediates $\left[\mathrm{Ag}_{37}(\mathrm{SG})_{21}, \mathrm{Ag}_{36}(\mathrm{SG})_{20}\right]$

along with the $\mathrm{Ag}_{35}(\mathrm{SG})_{18}$ main product 
Scheme 2. Depiction of the reversible transformation (steps 1-3) of $\operatorname{Ag}_{35}(\mathrm{SG})_{18}$ into $\operatorname{Ag}_{44}(4-$ FTP $)_{30}$. The transformation $\operatorname{Ag}_{35}(\mathrm{SG})_{18} \rightarrow \mathrm{Ag}_{44}(4-\mathrm{FTP})_{30}$ occurs in one step, whereas the reverse requires multiple steps involving intermediate cluster sizes.

\section{Theoretical model for ligand-induced resizing of NCs}

The experimental results described above pose a central question: what is the reason and mechanism behind the ligand-induced NC resizing from one narrow size distribution to another? One expects Ostwald ripening to initially (upon nucleation) cause the size distribution of clusters in a conservative system to broaden with time, while organic ligands inhibiting broadening. However, why and how the size distribution can be narrowed remains unclear. Therefore, we developed a model to explain the NC resizing phenomenon that occurs during ligand-exchange that fits within the general framework of reverse coarsening. In our model, the only way that cluster sizes may change is due to mass transfer between existing clusters; it is unlikely that new clusters will be nucleated during ligand-exchange. Classical coarsening, or Ostwald ripening, is driven by the tendency of the total surface energy of the cluster ensemble in a solution to decrease towards a minimum. In the case of solution-containing ligands, the binding of the ligands to the surface atoms contributes to the surface energy $(\gamma)$ of the atomic clusters and can produce a negative surface energy if the ligand-surface binding energy $\left(\varepsilon_{b}\right)$ is large enough. Indeed, this inversion happens when $\varepsilon_{b}$ exceeds the binding energy of the surface atom with its missing neighbors. In such circumstances, the atomic chemical potential of smaller clusters is smaller than that of the larger ones, which drives atomic migration from large to small clusters. Such an effect is the opposite of the typical classical phenomena of Ostwald ripening and is thus termed reverse coarsening. ${ }^{35}$ The ligand-free surface energy of metallic clusters is always positive $(\gamma>0)$ and depends on cluster size such that smaller clusters have a higher $\gamma^{41-43}$ 
Therefore, the size of clusters with bound ligands, and in thermodynamic equilibrium with the solution, is finite and depends on both $\varepsilon_{b}$ and $\gamma$. Any shape and geometry effects of the ligands, all empirically known parameters seen to influence cluster size, ${ }^{44}$ can effectively be included in the $\varepsilon_{b}$, which for the sake of simplicity is assumed to be a scalar quantity in our treatment here.

Given the outlined concepts and assumptions, the time evolution of spherical atomic NCs can be described by the classical Ostwald ripening process by taking into account the sizedependent surface energy and its renormalization by ligands bound to cluster surfaces. The size distribution of clusters, already nucleated and grown prior to ligand-exchange, may only evolve further by transfer of atoms between clusters. Assuming that the process of atomic exchange between clusters is limited by attachment-detachment events (the Wagner approximation) ${ }^{45}$ the evolution of the $i$-th cluster with radius $R_{i}$ (measured in the units of inter-atomic distance) can be described by the equation

$$
\frac{d R_{i}}{d t}=K \cdot\left(n-n_{G T}\left(R_{i}\right)\right)
$$

where $K$ is a kinetic constant, $n_{G T}\left(R_{i}\right)$ is the Gibbs-Thomson concentration, and $n$ is the mean field concentration of atoms in the solution. The latter is determined using mass conservation for all clusters ${ }^{35}$

$$
\frac{d}{d t} \sum_{i=1}^{N} \frac{4}{3} \pi R_{i}^{3}=\sum_{i=1}^{N} 4 \pi R_{i}^{2} \frac{d R_{i}}{d t}=\sum_{i=1}^{N} 4 \pi K R_{i}^{2} \cdot\left(n-n_{G T}\left(R_{i}\right)\right)=0 \rightarrow n=\frac{\sum_{i=1}^{N} R_{i}^{2} \cdot n_{G T}\left(R_{i}\right)}{\sum_{i=1}^{N} R_{i}^{2}}
$$

The Gibbs-Thomson concentration is the concentration for which the cluster is in equilibrium with its surrounding solution and is determined from the equation ${ }^{35}$

$$
n_{G T}\left(R_{i}\right)=\exp \left[-\frac{\varepsilon}{k_{B} T}+\frac{2 \Gamma\left(R_{i}\right)}{k_{B} T R_{i}}\right], \Gamma\left(R_{i}\right)=\gamma_{0}+\frac{\gamma_{1}}{R_{i}}-k_{B} T \ln \left(1+n_{L} \cdot \exp \left(\frac{\varepsilon_{b}}{k_{B} T}\right)\right)
$$


where $\varepsilon$ is the atomic cohesive energy, $\gamma=\gamma_{0}+\gamma_{1} / R\left(\gamma_{0}, \gamma_{1}>0\right)$ is the size-dependent (ligandfree) surface energy, $\Gamma(R)$ is the effective surface energy renormalized by molecular ligands, $n_{L}$ is the concentration of ligands in the solution, and $\varepsilon_{b}$ is the atom-ligand binding energy (all energy parameters are given per atom). Using Eqs (1)-(3) we simulated the time evolution of $10^{5}$ clusters for different values of $\varepsilon_{b}$ to determine if an ensemble of clusters with a narrow size distribution can really exist in the solution. At $\varepsilon_{b}>10 k_{B} T$, cluster size distribution noticeably narrows with time, indicating a regime of reverse coarsening that results in a monodisperse cluster ensemble. While for $\varepsilon_{b}<9.5 k_{B} T$, the size distribution gradually broadens as expected in the case of classical Ostwald ripening.

Qualitatively, the existence of a stable ensemble of identical clusters where cluster size is dependent on atom-ligand binding energy can be understood as follows: a high $\varepsilon_{b}$ reduces cluster size to ensure a higher surface-to-volume ratio, which maximizes the number of bound ligands. On the other hand, the surface energy $\gamma=\gamma_{0}+\gamma_{1} / R$ increases with decreasing $R$, which tends to increase the cluster size towards a lower surface-to-volume ratio. ${ }^{41-43}$ An equilibrium is reached when the two effects balance each other for some cluster radius. Interestingly, this equilibrium happens only when all clusters are identical and thereby have the same chemical potential for their constituent atoms. If the $\varepsilon_{b}$ is lowered by replacing ligands, then the balance is achieved at a lower value of $\gamma$, corresponding to a higher value of the cluster radius $R$.

According to this model, ligand replacements that affect $\varepsilon_{b}$ can change the cluster size. This effect is illustrated in Figure 4, which shows that the decrease in the ligand-atom binding energy from $\varepsilon_{b}=11.5 k_{B} T$ down to $\varepsilon_{b}=11.2 k_{B} T$ results, at almost any point in the clusters' 
evolution, in an increase of equilibrium cluster radius. Physically, this process occurs by smaller clusters supplying their mass to larger clusters for the latter to reach an equilibrium value. If, however, the reverse process is initiated, the dependence is not as simple. When $\varepsilon_{b}$ is increased, the final equilibrium value of the cluster radius depends on the point in the evolution curve where the ligand-exchange began. In this instance, larger clusters will transfer their mass to smaller ones to ensure thermal equilibrium. A problem arises when most of the smaller clusters have grown and only a few remain to accommodate the mass of the larger ones. This exceeding mass, which resulted from dissolved bigger clusters, generates the super-saturation of the solution. In order to achieve true equilibrium, extra clusters have to nucleate and consume the solution super-saturation. This nucleation, however, may take much longer to achieve. Such a picture is qualitatively consistent with the experimental observations described above in which the downsizing of clusters (Figure 3) was much slower than the up sizing of clusters (Figure 2) and proceeded through some intermediate stage with a broad enough size distribution.

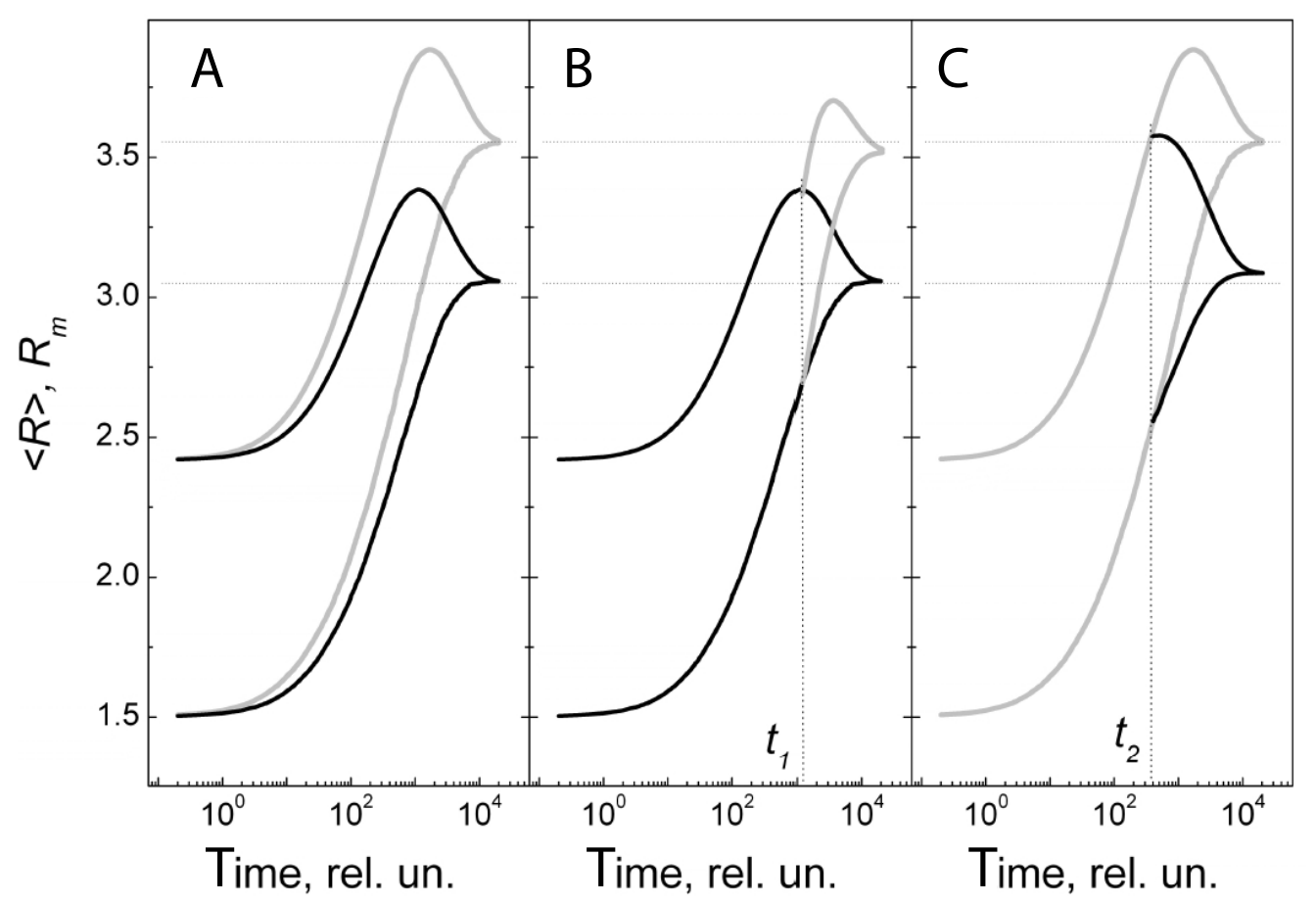


Figure 4. Time evolution of average $<\mathrm{R}>$ and maximum $\mathrm{R}_{\mathrm{m}}$ radii for an ensemble of $10^{5}$ clusters with initial sizes spread according to Gaussian distribution with $\langle R\rangle=1.5$ and $\sigma=0.25$ obtained by numerically solving Eqs (1)-(3) (A) for $\varepsilon_{b}=11.2 k_{B} T$ - gray lines and $\varepsilon_{b}=11.5 k_{B} T$ - black lines. Convergence of the radii indicates formation of monodisperse clusters. (B) Evolution of the radii after $\varepsilon_{b}$ is decreased at the intermediate time point $t_{1}$ from $11.5 k_{B} T$ down to $11.2 k_{B} T$. The radii trajectories shown in gray from the point $t_{l}$ converge on the value closest to the equilibrium cluster radius $r_{e q}=3.55$. (C) Evolution of the radii after $\varepsilon_{b}$ is increased at the intermediate time point $t_{2}$ from $11.2 k_{B} T$ up to $11.5 k_{B} T$. The radii trajectories shown in gray from the point $t_{2}$ converge on the value closest to the true equilibrium radius $r_{\mathrm{eq}}=3.05$. Note that reaching the equilibrium cluster size after increasing the $\varepsilon_{b}$ requires a broader cluster size distribution (see the difference $R_{m}-\langle R\rangle$ at $\mathrm{t}_{2}$ in $(\mathrm{C})$ ) than that after decreasing $\varepsilon_{b}$ as indicated by $R_{m}-\langle R\rangle$ at $t_{1}$ in $(\mathrm{B})$

\section{Size tunability of NCs via ligand-exchange}

Encouraged by the implications of the above theoretical model for tuning NC size, we looked into a wide range of thiols as incoming ligands in our ligand-exchange scheme including 3,4-difluorothiophenol (3,4-DFTP), 4-(trifluoromethyl)thiophenol $\quad$ (4-TFMTP), paramercaptobenzoic acid (p-MBA), 2-fluorothiophenol (2-FTP), 2-phenylethanethiol (PET), cyclohexanethiol (CHT), and 4-tertiarybutylbenzylthiol (BBS) (see Figure 5A for molecular structures). These thiols were used as substitutes for 4-FTP in the ligand-exchange conversion of $\mathrm{Ag}_{35}(\mathrm{SG})_{18}$. Optical absorption spectra of the ligand-exchange-induced products of $\mathrm{Ag}_{35}(\mathrm{SG})_{18}$ with different ligands are shown in Figure 5B. Formation of $\operatorname{Ag}_{44}(\mathrm{SR})_{30}$ was observed in the case of 3,4-DFTP. It is reasonable to attribute the structural similarity between 4-FTP and 3,4-DFTP as the reason for the formation of $\mathrm{Ag}_{44}$. On the other hand, the 2-FTP-exchanged product has absorption features that are substantially different from $\mathrm{Ag}_{44}$ (implying the formation of a 
different sized cluster), probably as a result of the proximity of the $\mathrm{F}$ atom to the $\mathrm{S}$ anchoring the ligand to the surface, potentially perturbing ligand confirmation and its binding to the surface (in comparison to 4-FTP and 3,4-DFTP). Other ligand-exchange-induced products also showed the characteristic nonplasmonic cluster-like absorption features. The PET-exchanged product had two absorption peaks at 550 and $650 \mathrm{~nm}$ and the exchanged product with CHT had a broad feature around $450 \mathrm{~nm}$. The BBS ligand-exchange product had a UV-vis peak at $505 \mathrm{~nm}$ and a shoulder peak around $620 \mathrm{~nm}$. 4-TFMTP was found to induce the formation of $\operatorname{Ag}_{44}(4-$ TFMTP) $)_{30}$-like clusters, whereas p-MBA seemed to induce the formation of a product similar to plasmonic silver nanoparticles (Figure S9 in SI). While the conversion yield of clusters starting from $\operatorname{Ag}_{35}(\mathrm{SG})_{18}$ was about the same ( 60-65 wt\% for all thiols with the exception of 4-FTP and 3,4-DFTP, which was $\sim 75 \mathrm{wt} \%$ ), the rate of formation of ligand-exchange-induced NC products seems to take on an inverse trend with the bulkiness of an incoming ligand in the following the order: 3,4-DFTP $>$ 4-FTP $>$ PET $>$ BBS $>$ CHT.

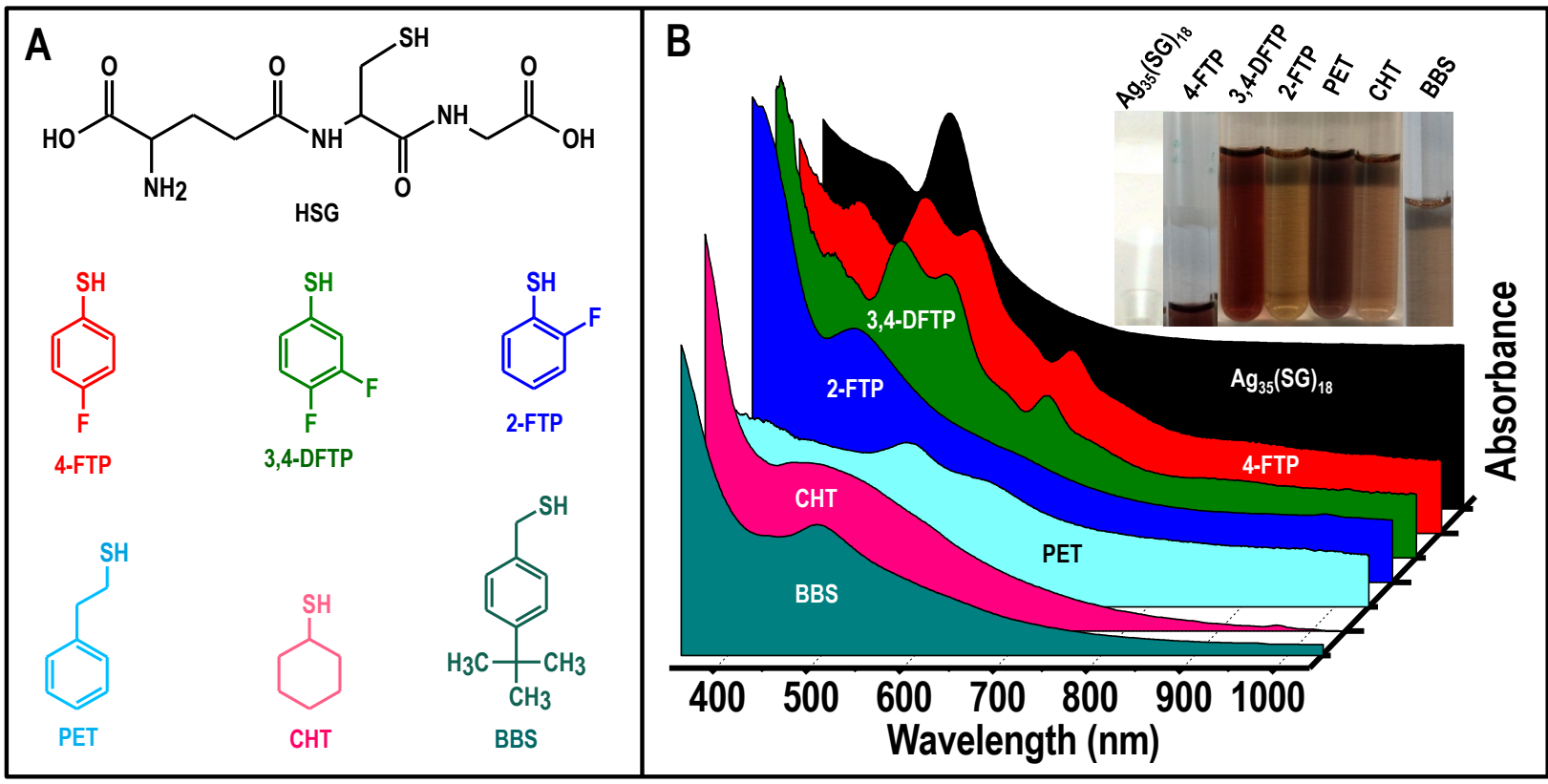


Figure 5. (A) Molecular structures of the various thiol ligands used for the ligand-exchange study. (B) UV-vis absorption spectra of $\mathrm{Ag}_{35}(\mathrm{SG})_{18}$ and its ligand-exchanged products with different thiols, 4-FTP, 3,4-DFTP, 2-FTP, PET, CHT, and BBS. Corresponding photographs of solutions are shown in the inset.

MALDI MS, an essential tool for characterizing nanoparticles ${ }^{46,47}$ and nanocrystals, ${ }^{48}$ was employed to determine the approximate compositions of the clusters formed after ligandexchange, following attempts to analyze them with ESI MS yielded no clearly interpretable signals. MALDI MS data of ligand-exchange-induced products of $\operatorname{Ag}_{35}(\mathrm{SG})_{18}$ with PET, BBS, and CHT are presented in Figure 6. Data were collected at threshold laser powers to minimize cluster fragmentation; however, the MALDI MS of $\operatorname{Ag}_{35}(\mathrm{SG})_{18}$ had a single sharp peak at $\mathrm{m} / \mathrm{z}$ $\sim 6.7 \mathrm{kDa}$ caused by fragmentation (Figure S1 in SI). The BBS-exchanged NC product had a peak at $\sim 11.3 \mathrm{kDa}$ assigned to be $\mathrm{Ag}_{\sim 55}(\mathrm{BBS})_{\sim 30}$. The optical absorption spectrum and MALDI MS results of this cluster agreed well with a recent report by Chakraborty et al. ${ }^{49}$ The PET-exchanged product had a single peak around $13.3 \mathrm{kDa}$ that we tentatively assigned to $\mathrm{Ag}_{\sim 75}(\mathrm{PET})_{\sim 40}$. In fact, absorption features of this cluster closely resemble the features of a previously known $\mathrm{Ag}_{\sim 68}(\mathrm{BBS})_{\sim 34}$ cluster, hinting at their equivalent, yet imprecisely determined cluster size. ${ }^{50} \mathrm{CHT}-$ exchanged product exhibits two prominent peaks at $\sim 29.8$ and $\sim 15.0 \mathrm{kDa}$. The former peak could be attributed to $\operatorname{Ag}_{\sim 200}(\mathrm{CHT})_{\sim 70}$ while the latter may correspond to the doubly charged state of same NC. The laser intensity-dependent MALDI MS study of CHT-exchanged product of $\mathrm{Ag}_{35}(\mathrm{SG})_{18}$ indicates the loss of ligands using high-powered lasers due to fragmentation. This indicates the fragility of Ag clusters as laser power increased. As a result, peaks at $\sim 29.8$ and $\sim 15.0 \mathrm{kDa}$ shifted to $\sim 23.2$ and $\sim 11.6 \mathrm{kDa}$, respectively (Figure S10 in SI). The mass spectra of 
the various clusters shown in Figure 6 demonstrate the effectiveness of ligand-exchange in tuning the sizes of NCs. Moreover, based on the observation of nearly singular peaks in the mass spectra, it is reasonable to assume that the clusters formed are likely to be monodisperse.

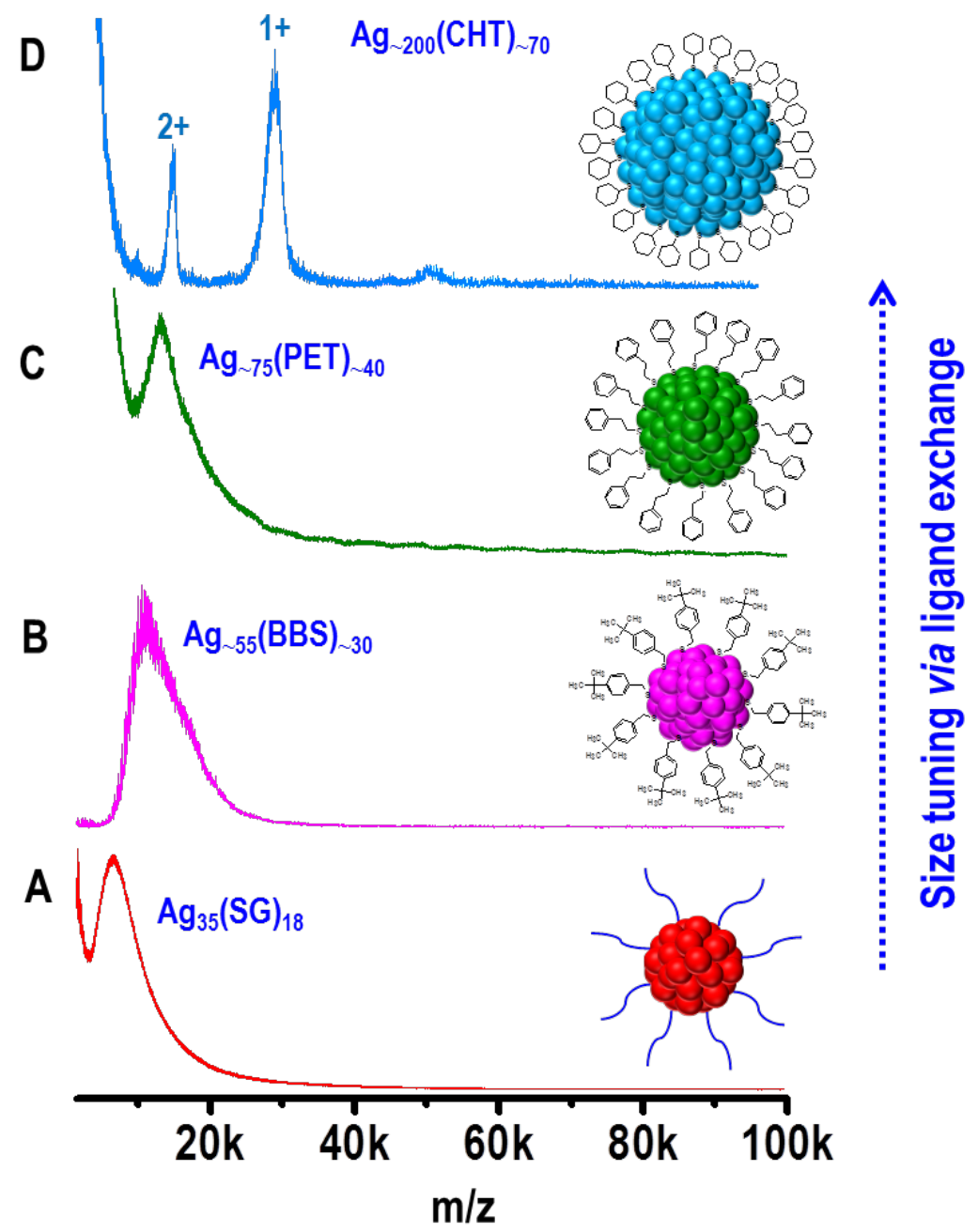

Figure 6. MALDI MS of (A) $\mathrm{Ag}_{35}(\mathrm{SG})_{18}$ and its ligand-exchange-induced products (B-D) with BBS, PET, and CHT, respectively. Schemes of clusters formed after the ligand-exchangeinduced growth of $\mathrm{Ag}_{35}(\mathrm{SG})_{18}$ are also seen in A-D. For simplicity, HSG on $\mathrm{Ag}_{35}$ is depicted in a simple format instead of in its molecular structure. 


\title{
CONCLUSION
}

We presented a ligand-induced strategy for the size tuning of silver NCs. By studying this transformation in detail in $\mathrm{Ag}_{35}(\mathrm{SG})_{18}$ and $\mathrm{Ag}_{44}(4-\mathrm{FTP})_{30}$, we showed that it is a reversible transformation that can lead to either growth $\left[\mathrm{Ag}_{35}(\mathrm{SG})_{18}\right.$ to $\left.\operatorname{Ag}_{44}(4-\mathrm{FTP})_{30}\right]$ or shrinkage $\left[\operatorname{Ag}_{44}(4-\right.$ FTP $)_{30}$ to $\left.\mathrm{Ag}_{35}(\mathrm{SG})_{18}\right]$. The process of growth occurs rapidly in a single step, while the reverse reaction proceeds slowly through intermediate cluster sizes. This is the first theoretical model available to explain this ligand-induced process. The model predictions are in good agreement with the experimental observations. In addition, the model underscores the critical role played by the ligand-metal binding energy in determining the final NC size. This insight led us to examine experimentally the use of ligand-exchange as a versatile approach to tune NC size. We demonstrated the validity of this approach by exchanging the ligand on $\operatorname{Ag}_{35}(\mathrm{SG})_{18}$ with a variety of thiols, through which we obtained NCs ranging in size from 50 to 200 silver atoms. This combined theoretical and experimental approach offers a general framework for using ligandexchange as a means to explore the rich landscape of NCs for silver or other compositions.

\section{ASSOCIATED CONTENT \\ Supporting Information \\ Optical, AUC, and mass spectral characterization of $\mathrm{Ag}_{35}(\mathrm{SG})_{18} ; \mathrm{UV}$-vis, SEM EDAX, elemental analysis and AUC of 4-FTP-exchanged $\mathrm{Ag}_{35}(\mathrm{SG})_{18}$; UV-vis, PAGE, ESI MS of HSG-exchanged $\mathrm{Ag}_{44}(4-\mathrm{FTP})_{30}$. This material is available free of charge via the Internet at http://pubs.acs.org.}

\author{
AUTHOR INFORMATION \\ Corresponding Author
}


osman.bakr@kaust.edu.sa

\section{Notes}

The authors declare no competing financial interest.

\section{ACKNOWLEDGMENTS}

The authors acknowledge the use of KAUST's Core Labs.

\section{REFERENCES}

1. Desireddy, A.; Conn, B. E.; Guo, J.; Yoon, B.; Barnett, R. N.; Monahan, B. M.; Kirschbaum, K.; Griffith, W. P.; Whetten, R. L.; Landman, U.; Bigioni, T. P. Ultrastable silver nanoparticles. Nature 2013, 501, 399-402.

2. Yang, H.; Wang, Y.; Huang, H.; Gell, L.; Lehtovaara, L.; Malola, S.; Hakkinen, H.; Zheng, N. All-thiol-stabilized $\mathrm{Ag}_{44}$ and $\mathrm{Au}_{12} \mathrm{Ag}_{32}$ nanoparticles with single-crystal structures. Nat Commun. 2013, 4, 2422.

3. Chakraborty, I.; Govindarajan, A.; Erusappan, J.; Ghosh, A.; Pradeep, T.; Yoon, B.; Whetten, R. L.; Landman, U. The superstable $25 \mathrm{kDa}$ monolayer protected silver nanoparticle: measurements and interpretation as an icosahedral $\operatorname{Ag}_{152}\left(\mathrm{SCH}_{2} \mathrm{CH}_{2} \mathrm{Ph}\right)_{60}$ cluster. Nano Lett. 2012, 12, 5861-5866.

4. Zhang, X.; Yang, H. Y.; Zhao, X. J.; Wang, Y.; Zheng, N. F. The effects of surface ligands and counter cations on the stability of anionic thiolated $\mathrm{M}_{12} \mathrm{Ag}_{32}(\mathrm{M}=\mathrm{Au}, \mathrm{Ag})$ nanoclusters. Chin. Chem. Lett. 2014, 25, 839-843.

5. Stamplecoskie, K. G.; Kamat, P. V. Size-dependent excited state behavior of glutathionecapped gold clusters and their light-harvesting capacity. J. Am. Chem. Soc. 2014, 136, 11093-11099.

6. Wu, Z.; Chen, J.; Jin, R. One-pot synthesis of $\mathrm{Au}_{25}(\mathrm{SG})_{18} 2$ - and 4-nm gold nanoparticles and comparison of their size-dependent properties. Adv. Funct. Mater. 2011, 21, 177-183. 
7. Kothalawala, N.; Lee West IV, J.; Dass, A. Size-dependent molecule-like to plasmonic transition in water-soluble glutathione stabilized gold nanomolecules. Nanoscale 2014, 6, 683-687.

8. $\mathrm{Wu}, \mathrm{Z}$. Anti-galvanic reduction of thiolate-protected gold and silver nanoparticles. Angew. Chem. Int. Ed. 2012, 51, 2934-2938.

9. Bootharaju, M. S.; Deepesh, G. K.; Udayabhaskararao, T.; Pradeep, T. Atomically precise silver clusters for efficient chlorocarbon degradation. J. Mater. Chem. A 2013, 1, 611-620.

10. Gao, S.; Chen, D.; Li, Q.; Ye, J.; Jiang, H.; Amatore, C.; Wang, X. Near-infrared fluorescence imaging of cancer cells and tumors through specific biosynthesis of silver nanoclusters. Sci. Rep. 2014, 4.

11. Zhang, X. D.; Luo, Z.; Chen, J.; Shen, X.; Song, S.; Sun, Y.; Fan, S.; Fan, F.; Leong, D. T.; Xie, J. Ultrasmall $\mathrm{Au}_{10-12}(\mathrm{SG})_{10-12}$ nanomolecules for high tumor specificity and cancer radiotherapy. Adv. Mater. 2014, 26, 4565-4568.

12. Udayabhaskararao, T.; Pradeep, T. New protocols for the synthesis of stable Ag and Au nanocluster molecules. J. Phys. Chem. Lett. 2013, 4, 1553-1564.

13. Crasto, D.; Barcaro, G.; Stener, M.; Sementa, L.; Fortunelli, A.; Dass, A. $\mathrm{Au}_{24}(\mathrm{SAdm})_{16}$ nanomolecules: X-ray crystal structure, theoretical analysis, adaptability of adamantane ligands to form $\mathrm{Au}_{23}(\mathrm{SAdm})_{16}$ and $\mathrm{Au}_{25}(\mathrm{SAdm})_{16}$, and its relation to $\mathrm{Au}_{25}(\mathrm{SR})_{18} . \mathrm{J} . \mathrm{Am}$. Chem. Soc. 2014, 136, 14933-14940.

14. Li, G.; Jin, R. Atomically precise gold nanoclusters as new model catalysts. Acc. Chem. Res. 2013, 46, 1749-1758.

15. Negishi, Y.; Mizuno, M.; Hirayama, M.; Omatoi, M.; Takayama, T.; Iwase, A.; Kudo, A. Enhanced photocatalytic water splitting by $\mathrm{BaLa}_{4} \mathrm{Ti}_{4} \mathrm{O}_{15}$ loaded with $\sim 1 \mathrm{~nm}$ gold nanoclusters using glutathione-protected $\mathrm{Au}_{25}$ clusters. Nanoscale 2013, 5, 7188-7192.

16. Sakai, N.; Nakamura, S.; Tatsuma, T. Photovoltaic properties of $\mathrm{TiO}_{2}$ loaded with glutathione-protected silver clusters. Dalton Trans. 2013, 42, 16162-16165.

17. Yuan, X.; Setyawati, M. I.; Tan, A. S.; Ong, C. N.; Leong, D. T.; Xie, J. Highly luminescent silver nanoclusters with tunable emissions: cyclic reduction-decomposition synthesis and antimicrobial properties. NPG Asia Mater. 2013, 5, e39. 
18. Palmal, S.; Jana, N. R. Gold nanoclusters with enhanced tunable fluorescence as bioimaging probes. WIREs Nanomed. Nanobiotechnol. 2014, 6, 102-110.

19. Lin, C. A. J.; Yang, T. Y.; Lee, C. H.; Huang, S. H.; Sperling, R. A.; Zanella, M.; Li, J. K.; Shen, J. L.; Wang, H. H.; Yeh, H. I.; Parak, W. J.; Chang, W. H. Synthesis, characterization, and bioconjugation of fluorescent gold nanoclusters toward biological labeling applications. ACS Nano 2009, 3, 395-401.

20. Yu, Y.; Luo, Z.; Yu, Y.; Lee, J. Y.; Xie, J. Observation of cluster size growth in COdirected synthesis of $\mathrm{Au}_{25}(\mathrm{SR})_{18}$ nanoclusters. ACS Nano 2012, 6, 7920-7927.

21. Zhou, R.; Shi, M.; Chen, X.; Wang, M.; Chen, H. Atomically monodispersed and fluorescent sub-nanometer gold clusters created by biomolecule-assisted etching of nanometer-sized gold particles and rods. Chem. Eur. J. 2009, 15, 4944-4951.

22. Jin, R.; Qian, H.; Wu, Z.; Zhu, Y.; Zhu, M.; Mohanty, A.; Garg, N. Size focusing: A methodology for synthesizing atomically precise gold nanoclusters. J. Phys. Chem. Lett. 2010, 1, 2903-2910.

23. Wang, C.; Wang, Y.; Xu, L.; Shi, X.; Li, X.; Xu, X.; Sun, H.; Yang, B.; Lin, Q. A galvanic replacement route to prepare strongly fluorescent and highly stable gold nanodots for cellular imaging. Small 2013, 9, 413-420.

24. Xu, H.; Suslick, K. S. Sonochemical synthesis of highly fluorescent Ag nanoclusters. ACS Nano 2010, 4, 3209-3214.

25. Liu, S.; Lu, F.; Zhu, J. J. Highly fluorescent Ag nanoclusters: microwave-assisted green synthesis and $\mathrm{Cr}^{3+}$ sensing. Chem. Commun. 2011, 47, 2661-2663.

26. Adhikari, B.; Banerjee, A. Short-peptide-based hydrogel: A template for the in situ synthesis of fluorescent silver nanoclusters by using sunlight. Chem. Eur. J. 2010, 16, 13698-13705.

27. Xie, J.; Zheng, Y.; Ying, J. Y. Protein-directed synthesis of highly fluorescent gold nanoclusters. J. Am. Chem. Soc. 2009, 131, 888-889.

28. Woehrle, G. H.; Warner, M. G.; Hutchison, J. E. Ligand exchange reactions yield subnanometer, thiol-stabilized gold particles with defined optical transitions. J. Phys. Chem. B 2002, 106, 9979-9981. 
29. Niihori, Y.; Matsuzaki, M.; Pradeep, T.; Negishi, Y. Separation of precise compositions of noble metal clusters protected with mixed ligands. J. Am. Chem. Soc. 2013, 135, 49464949.

30. AbdulHalim, L. G.; Kothalawala, N.; Sinatra, L.; Dass, A.; Bakr, O. M. Neat and complete: Thiolate-ligand exchange on a silver molecular nanoparticle. J. Am. Chem. Soc. 2014, 136, 15865-15868.

31. Zeng, C.; Liu, C.; Pei, Y.; Jin, R. Thiol ligand-induced transformation of $\mathrm{Au}_{38}\left(\mathrm{SC}_{2} \mathrm{H}_{4} \mathrm{Ph}\right)_{24}$ to $\mathrm{Au}_{36}(\mathrm{SPh}-t-\mathrm{Bu})_{24}$. ACS Nano 2013, 7, 6138-6145.

32. Shibu, E. S.; Muhammed, M. A. H.; Tsukuda, T.; Pradeep, T. Ligand exchange of $\mathrm{Au}_{25} \mathrm{SG}_{18}$ leading to functionalized gold clusters: Spectroscopy, kinetics, and luminescence. J. Phys. Chem. C 2008, 112, 12168-12176.

33. Shichibu, Y.; Negishi, Y.; Tsukuda, T.; Teranishi, T. Large-scale synthesis of thiolated $\mathrm{Au}_{25}$ clusters via ligand exchange reactions of phosphine-stabilized $\mathrm{Au}_{11}$ clusters. J. Am. Chem. Soc. 2005, 127, 13464-13465.

34. Nimmala, P. R.; Dass, A. Au ${ }_{99}(\mathrm{SPh})_{42}$ nanomolecules: aromatic thiolate ligand induced conversion of $\mathrm{Au}_{144}\left(\mathrm{SCH}_{2} \mathrm{CH}_{2} \mathrm{Ph}\right)_{60}$. J. Am. Chem. Soc. 2014, 136, 17016-17023.

35. Burlakov, V. M.; Bootharaju, M. S.; Besong, T. M. D.; Bakr, O.; Goriely, A. Reversing Ostwald ripening. http://arxiv.org/abs/1412.6280.

36. Udayabhaskararao, T.; Bootharaju, M. S.; Pradeep, T. Thiolate-protected Ag $_{32}$ clusters: mass spectral studies of composition and insights into the Ag-thiolate structure from NMR. Nanoscale 2013, 5, 9404-9411.

37. AbdulHalim, L. G.; Ashraf, S.; Katsiev, K.; Kirmani, A. R.; Kothalawala, N.; Anjum, D. H.; Abbas, S.; Amassian, A.; Stellacci, F.; Dass, A.; Hussain, I.; Bakr, O. M. A scalable synthesis of highly stable and water dispersible $\operatorname{Ag}_{44}(\mathrm{SR})_{30}$ nanoclusters. J. Mater. Chem. A 2013, 1, 10148-10154.

38. Guo, J.; Kumar, S.; Bolan, M.; Desireddy, A.; Bigioni, T. P.; Griffith, W. P. Mass spectrometric identification of silver nanoparticles: The case of $\operatorname{Ag}_{32}(\mathrm{SG})_{19}$. Anal. Chem. 2012, 84, 5304-5308.

39. Bakr, O. M.; Amendola, V.; Aikens, C. M.; Wenseleers, W.; Li, R.; Dal Negro, L.; Schatz, G. C.; Stellacci, F. Silver nanoparticles with broad multiband linear optical absorption. Angew. Chem. Int. Ed. 2009, 121, 6035-6040. 
40. Harkness, K. M.; Tang, Y.; Dass, A.; Pan, J.; Kothalawala, N.; Reddy, V. J.; Cliffel, D. E.; Demeler, B.; Stellacci, F.; Bakr, O. M.; McLean, J. A. $\operatorname{Ag}_{44}(\mathrm{SR})_{30}{ }^{4-}$ : a silver-thiolate superatom complex. Nanoscale 2012, 4, 4269-4274.

41. Uppenbrink, J.; Wales, D. J. Structure and energetics of model metal clusters. J. Chem. Phys. 1992, 96, 8520-8534.

42. Jortner, J. Cluster size effects. Z. Phys. D - Atoms, Molecules and Clusters 1992, 24, 247275.

43. Lordeiro, R. A.; Guimaraes, F. F.; Belchior, J. C.; Johnston, R. L. Determination of main structural compositions of nanoalloy clusters of $\mathrm{Cu}_{\mathrm{x}} \mathrm{Au}_{\mathrm{y}}(\mathrm{x}+\mathrm{y} \leq 30)$ using a genetic algorithm approach. Int. J. Quantum Chem. 2003, 95, 112-125.

44. Whetten, R. L.; Gelbart, W. M. Nanocrystal microemulsions: surfactant-stabilized size and shape. J. Phys. Chem. 1994, 98, 3544-3549.

45. Wagner, C. Theorie der Alterung von Niederschlagen durch Umlosen (Ostwald-Reifung). Zeitschrift fur Elektrochemie, Berichte der Bunsengesellschaft für physikalische Chemie 1961, 65, 581-591.

46. Kim, B. H.; Chang, H.; Hackett, M. J.; Park, J.; Seo, P.; Hyeon, T. Size characterization of ultrasmall silver nanoparticles using MALDI-TOF mass spectrometry. Bull. Korean Chem. Soc. 2014, 35, 961-964.

47. Kumara, C.; Zuo, X.; Ilavsky, J.; Chapman, K. W.; Cullen, D. A.; Dass, A. Super-stable, highly monodisperse plasmonic Faradaurate-500 nanocrystals with 500 gold atoms: $\mathrm{Au}_{\sim 500}(\mathrm{SR})_{\sim 120} . J$. Am. Chem. Soc. 2014, 136, 7410-7417.

48. Kim, B. H.; Shin, K.; Kwon, S. G.; Jang, Y.; Lee, H. S.; Lee, H.; Jun, S. W.; Lee, J.; Han, S. Y.; Yim, Y. H.; Kim, D. H.; Hyeon, T. Sizing by weighing: characterizing sizes of ultrasmall-sized iron oxide nanocrystals using MALDI-TOF mass spectrometry. $\mathrm{J}$. Am. Chem. Soc. 2013, 135, 2407-2410.

49. Chakraborty, I.; Mahata, S.; Mitra, A.; De, G.; Pradeep, T. Controlled synthesis and characterization of the elusive thiolated $\mathrm{Ag}_{55}$ cluster. Dalton Trans. 2014, 43, 1790417907.

50. Ghosh, A.; Pradeep, T. Synthesis of atomically precise silver clusters by using the miscibility principle. Eur. J. Inorg. Chem. 2014, 2014, 5271-5275. 


\section{Table of Contents}

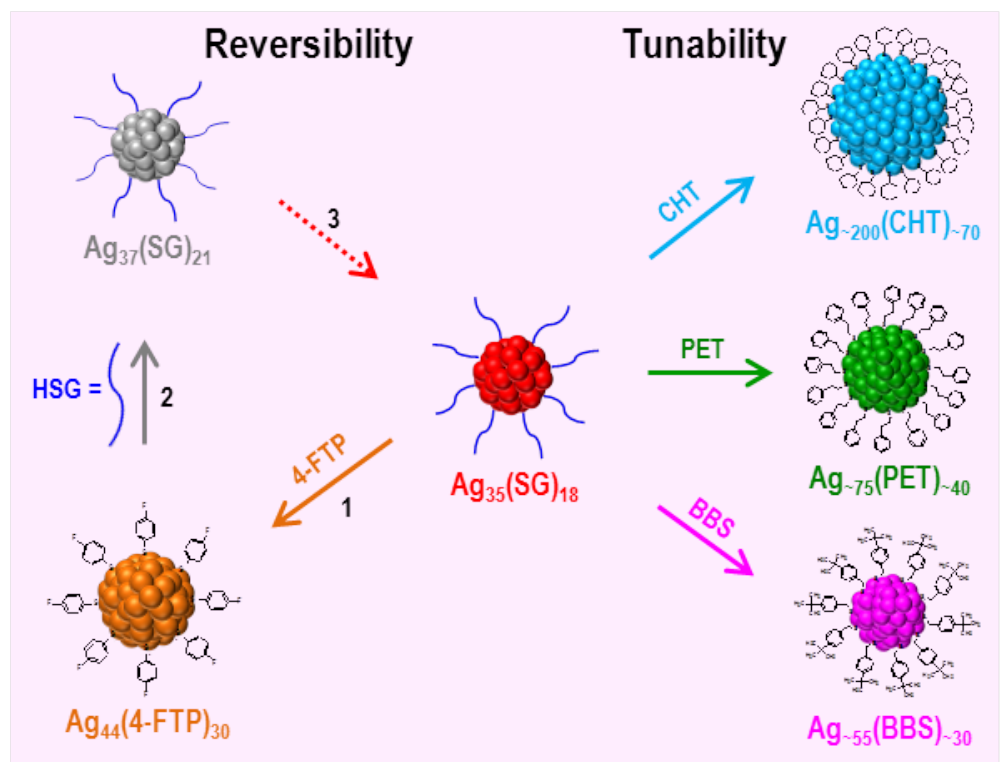

ACS Paragon Plus Environment 